\title{
A SYSTEMIC FUNCTIONAL PERSPECTIVE ON THE USE OF RHETORICAL DEVICES IN HILLARY CLINTON'S SPEECHES
}

\author{
Pham Thi Minh Phuong* \\ Department of Language Training and Professional Development, \\ VNU University of Languages and International Studies, \\ Pham Van Dong, Cau Giay, Hanoi, Vietnam
}

Received 23 January 2017

Revised 19 May 2017; Accepted 22 May 2017

\begin{abstract}
In this paper, attempts are made to analyze the use of rhetorical devices in Hillary Clinton's speeches. The analytical framework of the study is adapted from So (2005) which synthesizes Tribble's (2002) framework with the SFL's notion of metafunction of language. The data of the research contain ten Hillary Clinton's speeches from 2010 to 2016. Both the quantitative and qualitative methods are adopted to analyze the data. The results show that in certain contextual factors, five rhetorical devices including metonymy, repetition, irony, metaphor, and parallelism are exerted; and two last listed devices are employed the most frequently. The use of five rhetorical devices not only contributes to creative expression of message, but also boosts up persuasive effects on the audience.
\end{abstract}

Keywords: rhetorical devices, Systemic Functional Linguistics

\section{Introduction}

For years, the relationship between language and politics has been of great interest to many scholars and researchers. As a typical example, Joseph (2006) states that language is political from top to bottom by exemplifying the numerous ways in which politics and language interact and are ultimately dependent upon one another. Thanks to that connection, it is obvious that language is one of the most effective instruments of persuasion. Accordingly, almost all of the politicians are good at eloquence. Hilary Clinton, whether in the role of the First Lady of the United States, as the Head of Department of State, or as a presidential candidate, has long been famous for her intelligence, strategic position, ambition, and eloquence. The speeches she made have

* Tel.: 84-979572860

Email: phuongpham.anto@gmail.com always created huge influence on the audience. Therefore, this study is aimed to look closely at Hilary Clinton's use of rhetorical devices in the light of Systemic Functional Linguistics (SFL). Undeniably, SFL incorporates many of the more socio-cultural branches developed within linguistics in the second half of the twentieth century, such as pragmatics, sociolinguistics, discourse analysis, and etc. This enables SFL to account for both language structure and language use, which helps the researcher have a complete view of employing rhetorical devices in political speeches.

\section{Theoretical background}

\subsection{Systemic Functional Linguistics}

Systemic-Functional Linguistics (SFL) is a theory of language with the primary source claimed to be the work of Firth and his colleagues 
in London. SFL is, then, wholly developed in the work on the grammar of Chinese by Halliday (1956), and is considered the more comprehensive linguistic approach because of its focus on the function of language, not the structure of language, which distinguishes it from other traditional approaches. In other words, SFL focuses on language choices which language learners employ to convey different meanings. Besides, SFL starts at social context, and looks at how language both acts upon, and is constrained by this social context.

Any analyses of language in use in the light of SFL necessitate the discussion of some key concepts, which include context, context of culture, context of situation, field, mode, tenor and genre.

\section{Context}

The notion of context is presented at the beginning of Halliday's account as the most important base to see the functions of language. As Halliday (1985) puts it, context conditions "how language works". Language use must always be seen through the prism of social context. No matter how good language is, it should be appropriate to the context of use. Context can be further divided into context of culture and context of situation.

\section{Context of Culture}

According to Halliday \& Matthiessen (2014), context of culture is interpreted as the environment of a system of higher-level meanings which contain both language and paralanguage. The relations of situation and culture are central to Halliday's conception of language as an open dynamic system, as a "vast, open-ended system of meaning potential, constantly renewing itself in interaction with its ecosocial environment" (Halliday, 1985).

\section{Context of Situation}

Halliday (1985) characterizes situations in terms of field (what is happening, to whom, where and when, why it is happening, and so on), tenor to the social relation existing between the interactants in a speech situation), and mode (the way the language is being used in the speech interaction). These three components offer a system helping illustrate any socio-linguistic occurrence, which makes it possible for the speakers or writers to orient themselves in the context of situation.

\section{Genre}

Genre is defined by Thompson (1994) as register plus purpose. The linguistic realisation of context of culture is termed genre while register is the linguistic realisation of context of situation. Therefore, the analysis of genre informs about what the interactants do through language and how they arrange linguistic resources to succeed in accomplishing a certain purpose.

To sum up, in SFL, language is looked from the cultural context perspective, which differentiates SFL from other linguistic theories. In SFL view, language relates to human experience, which fits into social structure. Thus, language is not just a part of 'cognitive mechanism' (Reuter, 2000), but how people use it in social functions in certain culture.

\subsection{Rhetorical devices}

Rhetorical devices in Traditional Approach vs SFL

In the traditional view, a rhetorical device is defined as a technique that an author or a speaker uses to convey to the listener or reader a meaning with the aim of persuading him or her towards considering a topic from a different perspective, using sentences designed to encourage or provoke a rational argument from an emotional display of a given perspective or action. Simply, a rhetorical device is a use of language that is intended to have an effect on its audience through spoken or written forms. Especially, in traditional grammar, rhetoric is the study of style through grammatical and logical analysis. 
In SFL view; however, rhetoric is the study of how effective writing achieves its objectives. The term rhetoric in this new sense offers an analytical lens to investigate and concentrate on how to convey oneself accurately and effectually in connection with the subject of writing or speech and the audience, and to employ methods to identify the relations between texts and contexts (Jost\& Olmsted, 2004). In other words, any rhetorical devices must be understood in relation to context, as any linguistic choice is decided by context.

\section{Rhetorical device classification}

Many theoreticians including Taylor (1981), Little (1985), Lyons (1995), Thomas et al (2004) and Fahnestock (2011) keep discussing about rhetorical devices. However, the ways these scholars define and classify the different rhetorical devices are almost the same. In this paper, based on the existing classifications, the classification of rhetorical devices analyzed in this study could be summarized in Table 1.

\subsection{Research methods}

The method of the study was a combination of both quantitative and qualitative methods for an in depth analysis of the research topic. Although this study concentrated on examining the phenomena of the use of rhetorical devices in speeches qualitatively, the statistic data also informed about the general distribution of the devices in the speeches.

\subsection{Data}

The data of the present study were ten Hillary Clinton's speeches from 2010 to 2016 in three different roles. Three speeches were delivered when Hillary Clinton was in the role of Secretary of State, three others were made when she was in the role of a member of the Clinton Foundation, and the rest were delivered when she was a presidential candidate. The audience were ministers, CEOs or even just American inhabitants. All of the speeches which were approximately

Table 1. The adapted classification of five rhetorical devices

\begin{tabular}{|c|c|}
\hline Device & Description \\
\hline Metaphor & Metaphor is a way of comparing two different concepts based on similarities of analogies. \\
\hline Metonymy & Metonymy is the substitution for another with which it is closely associated. \\
\hline Repetition & $\begin{array}{c}\text { Repetition is a rhetorical device that involves the repetition of the same word, phrase or } \\
\text { sentence. }\end{array}$ \\
\hline Parallelism & $\begin{array}{c}\text { Parallelism is a device that uses words or phrases with a similar structure to express } \\
\text { several ideas. }\end{array}$ \\
\hline Irony & Irony is a device based on the opposition of meaning to the sense. \\
\hline
\end{tabular}

\section{Methodology}

\subsection{Research questions}

This paper aims to answer the following two research questions:

1. How are the five major rhetorical devices employed in Hilary Clinton's speeches?

2. How does the use of rhetorical devices contribute to conveying the message of the speaker and creating persuasive effect on the audience?
6000 words, were collected from reliable websites such as http://www.state.gov/.

Furthermore, the speeches are coded with the coding scheme as follows.

Speech (20YY_Sx): YY: The year of the speech, S: speech, $\mathrm{x}$ : the ordinal number of the speech in the same year. For example, 2014_S1 is the code of the first speech that Hillary Clinton delivered in 2014. 
3.4. Analytical framework of rhetorical devices in SFL

In this study, the analytical framework is constructed based on Halliday's description of the text - context relationship. The general analytical framework is composed of contextual analysis and content analysis, which is presented in Figure 1.The criteria for identifying and classifying rhetorical devices in the speeches are presented in Table 1 above; and the details of contextual analysis are presented in Table 2.

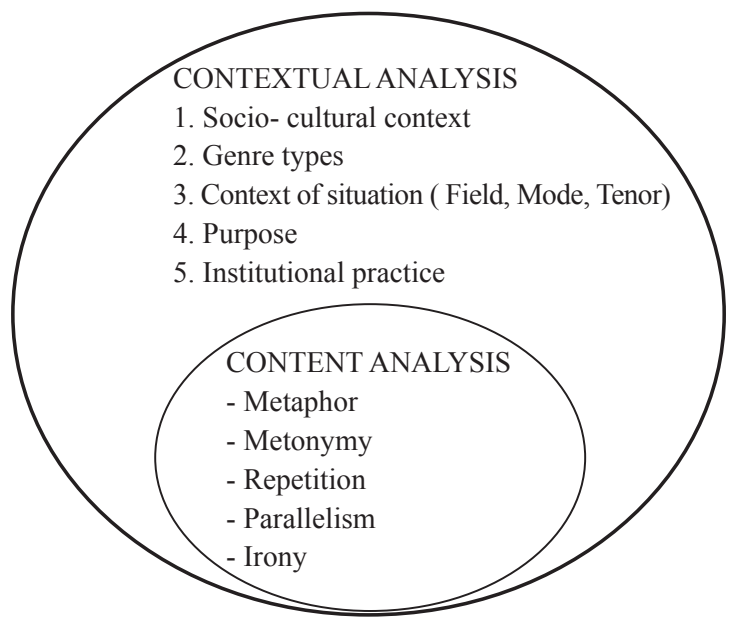

Figure 1. The relationship between the contextual analysis and content analysis
So (2005) did a research on the possibility of using newspaper genres and genre-based pedagogy to teach intermediate ESL learners to write school genres based on the framework of Tribble's one with the notion of metafunctions of language and intertextuality. The author selected two texts on the same issue to analyze and compare. That process involved some stages including analysing the generic conventions and structures of the texts and seeing how they were related to their contexts; finding out their overlaps and distinctions; and then discusing what student writers could draw from the newspaper genres when doing a designated writing task, in terms of content, form and organization. As a result, as So (2005)'s analytical framework included contextual analysis which was applied to examine the relationship between language use and context, it was beneficial to this paper.

Table 2. The contextual analysis is adapted from So, (2005)

\begin{tabular}{|l|l|}
\hline \multicolumn{1}{|c|}{ Contextual analysis } & \multicolumn{1}{c|}{ Probing questions } \\
\hline 1. Genre types and subtypes & $\begin{array}{l}\text { What is the name of the genre of which the text is an exemplar? Are there } \\
\text { any subtypes or subsets in this genre? }\end{array}$ \\
\hline $\begin{array}{l}\text { 2. Context of situation } \\
\text { a. Mode } \\
\text { b. Tenor }\end{array}$ & $\begin{array}{l}\text { What is the channel of communication? } \\
\text { What roles may be required of the speaker and hearers? Do they have } \\
\text { equal status and how is their affect and contact? }\end{array}$ \\
c. Field & What subject matter is the text about? \\
\hline 3. Purpose & $\begin{array}{l}\text { What are the communicative purposes of the text? How are they } \\
\text { achieved? How are they related to the rhetorical functions of the text? }\end{array}$ \\
\hline 4. Institutional practice & $\begin{array}{l}\text { In what institution is this kind of text typically produced? What } \\
\text { constraints and obligations does this discourse community impose on } \\
\text { speakers and hearers? Do the production and hearing processes influence } \\
\text { its structure and language? }\end{array}$ \\
\hline 5. Sociocultural context & $\begin{array}{l}\text { Are there any social, historical or cultural factors that make the text } \\
\text { appear the way it is? }\end{array}$ \\
\hline
\end{tabular}




\section{Findings and discussion}

\subsection{Findings}

\section{Overview of ten speeches}

In general, it can be said that there are three common characteristics of Hillary Clinton's speaking styles in the speeches from 2010 to 2016 in three different roles, which are presented as follows.

The first common characteristic is related to the content of the speech. Despite the main topic of each event, Hillary Clinton tended to mention some certain topics. The first topic that Hillary Clinton mentioned was the leadership of the United States. The second topic to be mentioned was her family: her grandfather, her grandmother, her parents, her husband and her daughter in almost all of her speeches, especially after her terms of office. This indicated that her family had a great impact on Hillary Clinton. The third topic to be referred to was the Democrat presidents. Finally, Hillary Clinton also mentioned both topics associated with her name as woman's rights and human's rights and global issues such as ISIS and climate change. It seems that she always knows how to link her strengths to the "hottest" topics.

The second common characteristic is the general structure of the speech. The speech was often sectioned into some constituents, the introduction and thanks, the body and the closing. In the part of the body, the constituents looked changeable depending on the certain context and her roles despite the same popular contents as stated above.

The third common characteristic is the degree of conciseness and unity. Under certain circumstances, the presentation could be more structured or less structured.
Realization of rhetorical devices in the ten chosen speeches

It could be realized from Figure $2 \mathrm{a}$ that parallelism was the most frequent device which accounted for 33\% of the total amount of analyzed stylistic figures. In the second position, showing a slight less by only $3 \%$ was metaphor. In the third position, metonymy which appeared 59 times took up $20 \%$. While repetition occurred 43 times equal to $14 \%$ and then played the fourth position of the most popular rhetorical devices Hillary Clinton employed. Finally, the least percentage of rhetorical devices in Hillary Clinton's speeches was irony with $4 \%$. It emerged only 10 times in the analyzed speeches from 2010 to 2016 .

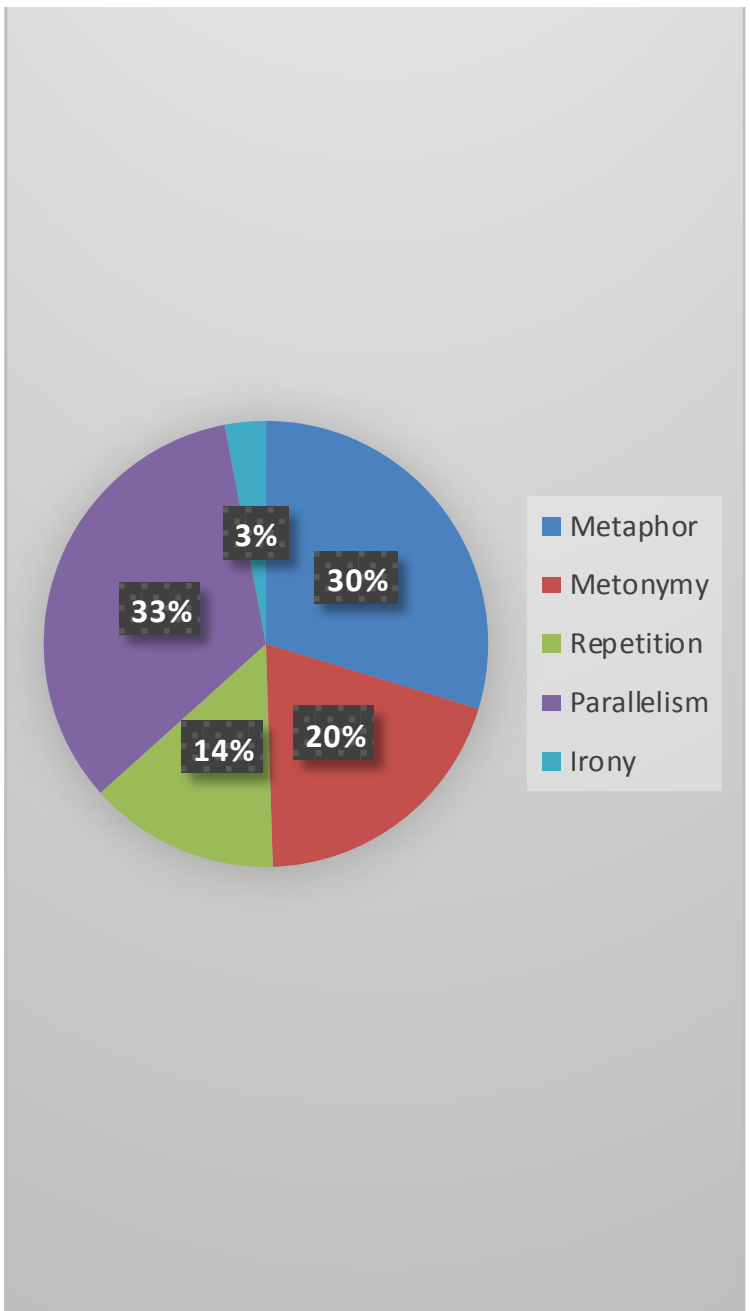

Figure 2a. Analysis of rhetorical devices 


\begin{tabular}{|c|c|}
\hline $\begin{array}{l}\text { 1. Genre type } \\
\text { and subtypes }\end{array}$ & $\begin{array}{l}\text { Persuasive speech. Subtypes of } \\
\text { highly persuasive, persuasive } \\
\text { and mildly persuasive. }\end{array}$ \\
\hline $\begin{array}{l}\text { 2. Context of } \\
\text { situation }\end{array}$ & \\
\hline a. Mode & $\begin{array}{l}\text { Spoken discourse in the mode } \\
\text { of conference, forum and } \\
\text { campaign speeches }\end{array}$ \\
\hline b. Tenor & $\begin{array}{l}\text { Hillary Rodham Clinton } \\
\text { (speaker) } \rightarrow \text { Audience (hearers). } \\
\text { Hillary Clinton always adopts an } \\
\text { appropriate tone }\end{array}$ \\
\hline c. Field & $\begin{array}{l}\text { American foreign policies, } \\
\text { human rights, LGBT, women } \\
\text { and Hillary's policies }\end{array}$ \\
\hline 3. Purpose & $\begin{array}{l}\text { Acknowledging, debating and } \\
\text { persuading audience to agree } \\
\text { with her arguments. }\end{array}$ \\
\hline $\begin{array}{l}\text { 4. Institutional } \\
\text { practice }\end{array}$ & $\begin{array}{l}\text { Appropriate language and clear } \\
\text { structure under constraints } \\
\text { imposed by certain institutions. } \\
\text { (CFR, EP Group, and etc) }\end{array}$ \\
\hline $\begin{array}{l}\text { 5. Sociocultural } \\
\text { context }\end{array}$ & $\begin{array}{l}\text { No noticeable influence to be } \\
\text { observed. There only some } \\
\text { problems affecting the production } \\
\text { of speech such as the Israeli- } \\
\text { Palestinian peace talks and } \\
\text { discrimination against LGBT. }\end{array}$ \\
\hline
\end{tabular}

Figure 2b. Analysis of context

As presented in Figure $2 \mathrm{~b}$, in terms of genre and subtypes, the genre of ten speeches was persuasive speech categorized into three subtypes: highly persuasive, persuasive and mildly persuasive. Secondly, the speeches were in three roles as Secretary of State, as member of the Clinton Foundation and as a presidential candidate. The audience came from different social status and occupation as stated in the data information. The fields were various from global issues to topics associated with Hillary Clinton such as human rights and ISIS. Above and beyond, all of the speeches had a general aim of persuading the audience to agree with her ideas.
Frequency of rhetorical devices in three periods

The following line chart demonstrates the frequency of rhetorical devices in speeches which Hillary Clinton made in three roles as Secretary of State, as a member of the Clinton Foundation and as a presidential candidate.

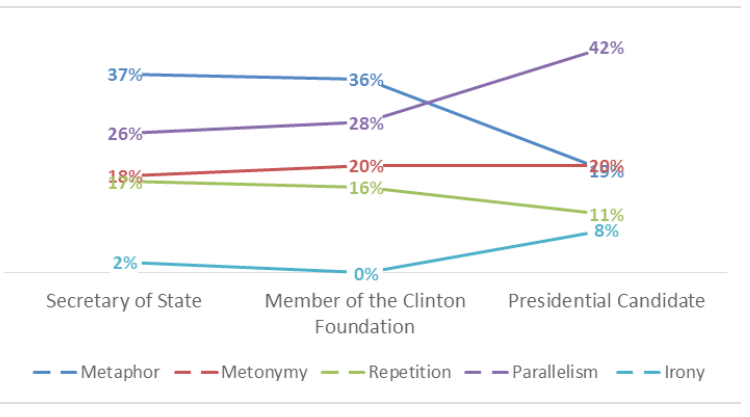

Figure 3. Frequency of rhetorical devices in three periods

Generally, Figure 3 indicated the evident change of using figurative devices in Hillary Clinton's speeches through different roles from 2010 to 2016. As could be seen from the chart, there were upward trends in the percentage of irony and parallelism. To be more detailed, parallelism increased sharply from $26 \%$ in 2010 to $42 \%$ in 2016 . Similarly, irony showed a less growth of $6 \%$. In contrast, the percentage of metaphor and repetition used by Hillary decreased over the period shown. Metaphor significantly went down to just over 19\%. Showing a similar trend, repetition fell from $17 \%$ to $11 \%$. Besides, the percentage of metonymy stayed stable at around $20 \%$ throughout the period.

\section{Discussion}

The impact of situational context on Hillary Clinton's use of rhetorical devices

It is undeniable that the factor of situational context has a certain effect on the use of rhetorical devices in Hillary Clinton's 
speeches. From the analyses of tenor in all ten chosen speeches, it can be said that tenor is also one of the most significant factors contributing to the appearance of five major rhetorical devices. It seems to be clear that the social position of the speaker and the audience have influence on the choice of rhetorical devices. When Clinton was Secretary of State and the audience were governmental officials, policy makers, and global thought leaders like in 2010_S1, 2011_S1 and 2012_S1, then the tendency to be observed was that she chose to employ metaphor and parallelism mostly.

Furthermore, field also affects the distribution of rhetorical devices. It could be concluded that when the speech was about women like in 2013_S1, 2014_S1 and 2014_ S2; and about foreign policies like in 2010_S1, 2012_S1, then metaphor tended to be chosen most; but when the speech was about human rights like in 2011_S1, then parallelism and metaphor were employed frequently.

\section{The impact of purpose on Hillary Clinton's use of rhetorical devices}

Purpose is observed to be the second important factor in the use of five rhetorical devices in ten chosen speeches. If the purpose of the speech was either raising awareness, or discussing, or encouraging like in 2010_S1, 2011_S1, 2012_S1, 2013_S1, 2014_S1,2, it appeared that Hillary Clinton tended to use metaphor and parallelism more than other devices. If the purpose of the speech was to convince the audience to vote for Clinton, there seemed to be an overwhelming use of parallelism and irony.

\section{The impact of genre subtypes on Hillary} Clinton's use of rhetorical devices

Genre subtypes are found to be the third impactful cause. It could be drawn out that once the genre subtype was highly persuasive like in 2015_S1, 2016_S1, 2016_S2 and
2016_S3, then Clinton had tendency to take advantage of parallelism. When the genre subtype was persuasive like in 2010_S1 and 2012_S1, she used both metaphor and parallelism frequently. When the genre was mildly persuasive like in 2013_S1, 2014_S1 and 2014_S2, it seemed that Hillary Clinton preferred to use metaphor more.

In conclusion, the influence of contextual factors on Hillary's use of rhetorical devices could be observed. Though no exact patterns for using figurative devices in Hillary Clinton's speeches could be specified, it was found that, in different situations, with different purposes, in different genres, Hillary flexibly chose to use rhetorical devices differently but all efficiently to achieve her goals.

\section{Contribution of rhetorical devices in Hillary} Clinton's speeches

From the analysis of context and content, it can be said that each device owns its distinctive characteristics. The effects of the devices on the conveyance of the intended message and on the purpose of persuading the audience are diverse.

\section{Metaphor}

Referring to conveyance of the message, it can be said that metaphor evokes the imagination to show what the speech means. Without doubt, the core of the speech is difficult to express, therefore, the speaker often uses metaphor through specific, detailed, memorable images to clarify it like the image "hearts are breaking" in 2014_S2. In this example, Hillary Clinton succeeded in showing deep sadness with that expression. Besides, metaphor is employed to send the meaning by transferring the emotional content that is already well understood. Thus, the audience with different experiences in different contexts can grasp things intuitively. As a result, this explains why the use of metaphor can affect the aim of persuading the audience successfully. 
Metaphor draws a connection between the audience and the topic through what they can understand. Additionally, people are easier to be made emotional and convinced by familiar images because they have the sympathy and experience of those things.

\section{Metonymy}

It is also claimed that metonymy also plays an important part in making the meaning suggestive, imagery and lively by creating concrete and vivid images in place of generalities. Regarding the effect of metonymy on Hillary Clinton's speeches, metonymy obviously contributes to creative expression, but it seems to be not as strong as metaphor can be.

Eg1: "They are also unlikely to disappear if those who promote or accept them are dismissed out of hand rather than invited to share their fears and concerns..."

The common interpretation of "out of hand" is that: something in people's hand is their own, and they can even control it, the things out of their hands are what they cannot control. In this example, the abstract concept of control was easily conceptualized by the specific action of holding in hands, so "out of hand" meant "out of control". The audience consequently could find it effortless to get the intended message which the speaker wanted to express. With a familiar comprehensible image, the audience are believed to share their agreement with the speaker.

\section{Repetition}

Hillary Clinton succeeded in taking advantage of the possible rhetoric effects of repetition, that is, she managed to arrange her words into the pattern nothing like our ordinary speech. Such a way of using repetition not only is stylistically appealing but also helps convey the message in a much more engaging and notable way. Repetition used by Hillary Clinton in her speeches could contribute to the purpose of focusing the audience on the point of the main significance. Consequently, it is understandable that repetition brings about persuasive effects on the audience.

Eg2: "So to chart a path forward for women and girls we have to understand how far we've come, yet how far we still have to go"

In the above example, Hillary Clinton wanted to urge her hearers to continue asking for women's equality as she called the campaign for women's equality "the unfinished business". This saying was like a slogan obsessing the audience and reminding them of that progress.

\section{Parallelism}

Generally, parallelism was employed by Hillary Clinton to emphasize the key points to the hearers directly. As a result, these parallel structures and powerful rhythm helped to highlight those points in the audience's mind, and thereby, the audience seemed to be persuaded naturally.

Eg3: "Throughout our history, through hot wars and cold, through economic struggles and the long march to a more perfect union, Americans have always risen to the challenges we have faced. That is who we are. It is in our DNA. We do believe there are no limits on what is possible or what can be achieved."

In this instance, Hillary Clinton wanted to put stress on the leading role of America. By using this parallelism, Hillary Clinton emphasized what she would do when becoming the president of the US, which was presented throughout the whole speech, and which had also been her ideal living for years.

\section{Irony}

In light of the effects of irony, the message is conveyed through pointing out the contradiction between reality and how things appear or what is expected. When a presenter 
uses irony, there is disagreement in regards to the behavior of intended characters, the words that they say, or the events that take place. It means that using irony is to apply indirect references instead of direct statements to point out the problematic relationship between the perceived and the truth. In fact, Hillary Clinton did not often use irony till nearly the end of the election campaign.

Eg4: Now, there may be some new voices in the presidential Republican choir, but they're all singing the same old song...A song called "Yesterday."

Irony worked in the contradiction: the "new voices" sang a song "Yesterday". Through this contradiction, Hillary Clinton pointed out the fact that nothing changed if the Republican got the White House.

The fact that Hillary Clinton employed irony more often when the election came to the last results seemed to be a change in her linguistic style.

Overall, the rhetorical devices of metaphor, metonymy, repetition, parallelism, and irony make a good contribution to the persuasion of the speeches. It is quite difficult to imagine exactly how the speech would look like without the use of these five rhetorical devices: no emphasis, no image, no rhythm, and even no consistency. Without the use of these rhetorical devices, it would be more challenging for the audience to perceive and interpret all the meanings that the presenter expressed. The audience might easily lose their attention and interest in the speeches, and their support for Hillary Clinton might be affected accordingly.

\section{Conclusion}

Conclusion 1: All of the five kinds of rhetorical devices, namely metaphor, metonymy, repetition, parallelism and irony appear in Hillary Clinton's speeches. Among total ten presentations with 303 times five devices used to achieve communicative purposes, 89 times are of metaphor, 59 times are of metonymy, 43 times are of repetition, 102 times are of parallelism and 10 times are of irony. Undoubtedly, the most dominant type of rhetorical devices is parallelism which accounts for one third of all figurative devices employed in these.

As observed from the data of this study, the use of these rhetorical devices is looked through the prism of context. Based on the analyses of context, it can be said that employing rhetorical devices is different in each certain context. Factors of context seem to have direct influences on the appearance of stylistic devices. These factors include genre type and subtypes, situational context, purpose, institutional place and sociocultural context. As mentioned previously, all of the speeches belong to the genre of persuasive which is divided into three subtypes; namely, highly persuasive, mildly persuasive and persuasive. However, the type of genre and its subtypes appear to be determined by the roles Hillary Clinton plays. It seems that the higher social position she stands at, the more persuasive her speech is. Therefore, situational context seems to be the deciding factor in shaping Hillary Clinton's linguistic style. In other words, as explained above in the Discussion, the factor of context of situation influences the application of five major stylistic devices. Except from the institutional place, it could not deny the effect of purpose and sociocultural context on the use of five rhetorical devices, which is stated in the previous part of this study.

Conclusion 2: Related to the contribution offive major rhetorical devices, it appears that the messages are expressed in a clearer and more graphic way, and accordingly produce 
the persuasive effects on the audience. The conclusion can be similar to other previous researches on the effects of some rhetorical devices such as Lakoff and Johnson (1980). However, this one is a strong affirmation of the effects that rhetorical devices produce. In detail, the application firstly can help to give emphasis on the important ideas in general. For example, the audience can get the main idea immediately through strongly repeated structures. Secondly, the use of rhetorical device brings imagery to Hillary Clinton's speeches. The powerful visual image appears quite frequently, which is considered the effective means of carrying the meaning to the audience. This also causes the transferring process of the core of the speech to become concise. Besides, it can show the connection between literal and figurative meaning of an item. Furthermore, the appearance of rhetorical devices such as metaphor gives the poetic and emotional features to the political speech. Above all, employing rhetorical devices in political speeches, especially ones about political problems leads to the persuasive effects of the speech. It is quite apparent that the use of rhetorical device makes them not dry as everybody used to expect. The arguments are not only attractive, but also informative and forceful. To a certain extent, using rhetorical devices increases the support from the audience and builds up the persuasion of the speech.

\section{Implications of the study}

These findings can be applied in EFL context in Vietnam in several ways:

Firstly, according to the detailed analysis, regarding to the realization of five rhetorical devices, it can be confirmed that all five rhetorical devices are applied to make the presentation more convincing.
No matter what kind of device is, the presentation becomes much more inspiring, impactful and also beautiful. As a result, this is a valuable lesson about making use of rhetorical devices in speeches, especially in political ones for orators. For teachers, these findings are indeed useful to teach speaking skills, presentation skills. Speaking tasks should be designed to elicit students' practice of varied manifestation modes of rhetorical means in their presentation. For students, it is essential for students to enhance the knowledge of rhetorical devices that is one of the most invaluable parts of the linguistic treasure. Every student can make a presentation but not all knows how to make it effective.

Secondly, these findings can be a source of reference for those who are interested in developing translating and critical thinking skills for language learners. To be more detailed, when teaching translating skills, teachers should ask students to seek for equivalent meaning of rhetorical devices in Vietnamese, compare and contrast them with those means in English, thus give students chances to enrich vocabulary, practice brainstorming and making decision on the most suitable language choices to be made when translating texts from source language to target language.

\section{References}

Fahnestock, J. (2011). Rhetorical Style: The Uses of Language in Persuasion. Oxford, Oxford University Press.

Halliday, M. A. K. (1956). Grammatical categories in Modern Chinese Transaction of the Philosophy Society. Oxford, Blackwell.

Halliday, M.A.K. (1985). An introduction to Functional Grammar. London, Baltimore, $\mathrm{Md}$.

Halliday, M. A. K and Matthiessen, C. M. I. M. (2014). Halliday's introduction to functional grammar, $4^{\text {the }}$ dn. London, Routledge.

Joseph, J. E. (2006). Language and Politics. Edinburgh, Edinburgh University Press. 
Jost, W and Olmsted, W. (2004). A Companion to Rhetoric and Rhetorical Criticism. Oxford, Blackwell.

Lakoff, G and Johnson, M. (1980). Metaphors We Live By. Chicago, Chicago University Press.

Little, G. (1985). Approach to Literature: An Introduction to Critical Study of Content Method in Writing. Australia, Science Press.

Lyons, J. (1995). Linguistic Semantics. An Introduction. Cambridge, Cambridge University Press.

Reuter, M. (2000). Language and Language Teaching. Retrieved 2015, November $20^{\text {th }}$ from https:/citrawida.wordpress.com/2013/09/25/howdoes-systemic-linguistics-differ-from-traditionaland-transformational-grammars-what-are-itsadvantages-and-disadvantages/.
So, B.P.C. (2005). From analysis to pedagogic applications: using newspaper genres to write school genres. Journal of English for Academic Purposes. Vol. 4, pp. 67-82.

Taylor, R. (1981). Understanding the elements of literature: its forms, techniques and cultural conventions. New York, St. Martin's Press.

Thomas, L., Waring, S., Singh, I., Peccei, J. S., Thornborrow, J. and Jones, J. (2004). Language, Society and Power: An Introduction, $2^{\text {nd }}$ edn. London, Routledge.

Thompson, G. (1994). Introducing Functional Grammar. London, Edward Arnold.

\title{
NGHIÊN CÚU VIẸC SỬ DỤNG PHƯƠNG TIẸN TU TÙ TRONG CÁC DIỄN THUYẾT CỦA HILLARY CLINTON THEO QUAN ĐIỂM CHỨC NĂNG HỆ THỐNG
}

\author{
Phạm Thị Minh Phương \\ Khoa Đào tạo và Bồi duõng Ngoại ngũu, Trường Đại học Ngoại ngũu, ĐHQGHN, \\ Phạm Văn Đồng, Cầu Giấy, Hà Nội, Việt Nam
}

Tóm tắt: Bài viết bàn về việc sử dụng các phương tiện tu từ trong các diễn thuyết của Hillary Clinton theo quan điểm chức năng hệ thống. Tác giả sử dụng khung phân tích của So (2005) tổng hợp từ khung phân tích của Tribble (2002) và khái niệm siêu chức năng của ngôn ngữ học chức năng hệ thống (SFL). Dữ liệu nghiên cứu bao gồm 10 bài phát biểu của Hillary Clinton từ năm 2010 đến năm 2016. Cả hai phương pháp nghiên cứu định lượng và định tính đều được sử dụng để phân tích dữ liệu. Kết quả cho thấy các tác nhân bối cảnh có ảnh hưởng đến việc sử dụng của 5 phương tiện tu từ: ẩn dụ, hoán dụ, phép lặp, phép song hành và phép châm biếm, trong đó, ẩn dụ và phép song hành là được xuất hiện nhiều nhất. Ngoài ra, việc sử dụng 5 phương tiện tu từ trên không chỉ giúp truyền tải thông điệp của các diễn thuyết một cách ấn tượng, mà còn tạo ra những hiệu ứng thuyết phục với người nghe.

Từ khóa: phương tiện tu từ, ngôn ngữ học chức năng hệ thống 